REVIEW

This paper is dedicated to the $70^{\text {th }}$ anniversary of the founding of Physiologia Bohemoslovaca (currently Physiological Research)

\title{
Men's Reproductive Alterations Caused by Bisphenol A and Its Analogues: A Review
}

\author{
Tomas JAMBOR ${ }^{1}$, Nikola KNIZATOVA ${ }^{2}$, Norbert LUKAC ${ }^{2}$ \\ ${ }^{1}$ BioFood Centre, Faculty of Biotechnology and Food Sciences, Slovak University of Agriculture in \\ Nitra, Slovak Republic, ${ }^{2}$ Department of Animal Physiology, Faculty of Biotechnology and Food \\ Sciences, Slovak University of Agriculture in Nitra, Slovak Republic
}

Received June 8, 2021

Accepted September 16, 2021

\begin{abstract}
Summary
Male reproductive functions are an important area affecting men's overall health and well-being. However, during the last years, there has been observed increasing incidence of male reproductive issues. The radical growth has been recorded parallelly with a massive expanse of industrialization and agricultural chemigation. Many groups of experts have begun to identify several potential factors and substances that may have adverse effects on men's reproductive health. Since then, xenobiotics have become a major concern of many scientific studies. There is evidence that most of them have multigenerational and transgenerational effects on reproductive health, which is a serious problem for our population. Bisphenol $A$ could be considered as one of the most studied endocrine disruptors. Until now, several negative effects of bisphenol A were associated with reduced weight testes, histological alterations, impairment spermatogenesis, and steroidogenesis as well as with testes or prostate cancer. Due to convincing evidence, bisphenol A has been started to replace by its analogues such as bisphenol $B, S, F$, in order to eliminate and suppress the risk of exposure to bisphenol A. However, it seems that a lack of toxicological analyses allows using of these hazardous substances in daily life. Their harmful effect was confirmed by the animal in vitro and in vivo models, while the epidemiological studies monitoring the impact of bisphenol analogues on men's reproductive health are markedly limited. This review provides information about the effects of bisphenol on reproductive health in men. At the same time, it is focused on physiological aspects of sperm viability, steroid hormone secretion, sperm motility, or testes histology in relation to bisphenols exposure.
\end{abstract}

\section{Key words}

Endocrine disruptors • Bisphenols • Men's • Reproduction

\section{Corresponding author}

Tomas Jambor, BioFood Centre, Faculty of Biotechnology and Food Sciences, Slovak University of Agriculture in Nitra, Tr. A. Hlinku 2, 94976 Nitra, Slovak Republic. E-mail: tomasjambor1@gmail.com

\section{Introduction}

With the progressive development of industries and technology, xenobiotics have brought significant potential risk to wildlife and human. Thousands of synthetic chemical compounds are currently registered for use in industry and agriculture, and hundreds of tons of these are produced by several countries every year. Our environment is daily exposed to the different substances released into it continually. The evaluation of the current content of xenobiotics in our environment is a very challenging task and the data vary depending on countries and other factors. The term xenobiotics includes a wide variety of substances such as natural compounds present in plant foods, synthetic compounds in medicines, food additives, as well as components of agricultural chemicals and food packaging materials. Everybody interacts with a large number of xenobiotics daily and it seems unlikely that we are able to avoid them. Regardless of the source or original intended use, substantial amounts of these chemicals end up in the soil, aquatic environment, atmosphere as well as in our body (Jambor 
et al. 2019, Saghir and Ansari 2019, Castellini et al. 2020). Soil xenobiotics include dioxins, polychlorinated biphenyls (PCBs), alkylphenols, or bisphenols which enter soils through the agrochemical's applications. However, the soil can be a habitat for many other xenobiotic pollutants including chlorinated solvents, ethylbenzenes, or pharmaceuticals residues. They are difficult to be degraded and $\mathrm{pH}$ or temperature factors of soil may affect their persistence/biodegradation (Salem et al. 2017). In the aquatic ecosystem are xenobiotics usually attached to organic matter, sediments, and the organisms that live there. Simultaneously, a high amount of these substances float in groundwater and watercourses. This is a global problem that threatens the survival of various forms of life on the planted, including humans, and consequently form the ecosystem as a whole. Some of the most important examples of xenobiotics present in the water are polycyclic aromatic hydrocarbons (PAHs), bisphenols, and PCBs (Ibor et al. 2019). Overleaf, the worldwide increase of pharmaceuticals available for human and veterinary medicine caused concern converting it into emerging contaminants that are currently detected in the watercourse. The main pathways that enable water pollution by xenobiotics are places dedicated to treating water, runoff of soils, and discharges from industrial areas and from hospitals or animal farming (Mezzelani et al. 2018). Humans and animals are dependent on the supply of oxygen from the air and its contamination may result in the varied intake of many toxic compounds with adverse health outcomes. The World Health Organization (WHO) has pointed out that more than half of the world's deaths are strongly affected by lifestyle but in addition also by the quality and pollution of outdoor air. Gaseous and particulate matter of air pollution includes components of plastics (bisphenols, alkylphenols, phthalates), components of consumer goods (parabens, fluorosurfactants), industrial chemicals (PCBs) as well as dioxins, heavy metals, and other endocrine-disrupting chemicals (EDCs) (Darbre et al. 2018).

Amongst all physiologic functions, those related to reproduction are probably uniquely essential for the survival of the living species without being vital for the individual. The male reproductive system's organs are responsible for the following functions: sperm and protective fluid must be produced, maintained, and transported, to discharge sperm within the female reproductive tract during sex, male sex hormones are produced and secreted to keep the male reproductive system in physiological condition (Alwaal et al. 2015). Unlike the female reproductive system, most of the male reproductive system is located outside of the body The male reproductive system contains the external genitals (the penis, testes and the scrotum) and internal parts, including the prostate gland, vas deferens and urethra. A man's fertility and sexual traits depend on the normal functioning of the male reproductive system, as well as hormones released from the brain (Clement and Giuliano 2015, healthdirect 2021). The male reproductive system is responsible for reproduction. It is made of the following parts: penis - the organ used for urination and sexual intercourse. It has spongy tissue, which can fill with blood to cause an erection. It contains the urethra, which carries both urine and semen, scrotum - this is a loose bag of skin that hangs outside the body, behind the penis. It holds the testes in place, testes (or testicles) these are a pair of egg-shaped glands that sit in the scrotum, on the outside of the body. They produce sperm and testosterone, which is the male sex hormone, epididymis - this is a highly coiled tube that lies at the back of the testes. All sperm from the testes must pass through the epididymis, where they mature and start to 'swim', vas deferens - this is a thick-walled tube joined to the epididymis. It carries sperm from the epididymis up to the prostate gland and urethra, prostate gland - this is a walnut-sized gland that sits in the middle of the pelvis. The urethra runs through the middle of it. It produces the fluid secretions that support and nourish the sperm, urethra - this is a tube that extends from the bladder to the external opening at the end of the penis. The urethra carries both urine and sperm, seminal vesicles - these are 2 small glands above the prostate gland that make up the majority of the fluid in semen (healthdirect 2021, Ittmann 2018, Senger 1997).

The hypothalamus, pituitary gland (both anterior and posterior portions), and testes form the hypothalamic pituitary gonadal axis. The hypothalamus secretes gonadotrophin releasing hormone $(\mathrm{GnRH})$ in a pulsatile fashion, which enters the hypophyseal portal system in order to reach the anterior pituitary gland. This stimulates the anterior pituitary gland to secrete two important hormones for reproduction, follicle-stimulating hormone (FSH) and luteinizing hormone (LH), as well as adrenocorticotropin, growth hormone, prolactin, and thyroid-stimulating hormone (TSH), all of which have poorly understood roles in reproduction at normal physiologic levels (Clavijo and Hsiao 2018, Sussman et al. 2008). LH and FSH affect testicular cells such as 
Leydig, Sertoli, and germ cells. In the testicle, Leydig cells produce testosterone, while Sertoli cells produce inhibin B. Both hormones feedback onto the anterior pituitary and the hypothalamus (Clavijo and Hsiao, 2018).

The conversion of cholesterol to glucocorticoids, mineralocorticoids, and sex steroids, which regulate development and physiology, is known as steroidogenesis. Steroidogenesis is regulated at multiple levels, principally by transcription of genes encoding steroidogenic enzymes and co-factors, and by their posttranslational modification. Steroidogenesis is frequently described in terms of glands, but it is best understood as a single process that occurs in each gland with cell typespecific variations. Primary organs for steroidogenesis in the male are the pair of testes and adrenal glands. In the testis, steroidogenesis is restricted to Leydig cells where conversion of cholesterol to testosterone. The majority of steroidogenic enzymes are hydroxysteroid dehydrogenases or cytochrome P450 enzymes, with posttranslational modifications and co-factors, particularly electron-donating redox partners, influencing their activities. Understanding steroidogenesis is crucial for rational steroid therapies, as it allows researchers to better understand sexual differentiation, reproduction, fertility, hypertension, obesity, and physiologic homeostasis (Bremer and Miller 2014).

\section{Male reproduction: a sensitive indicator of EDCs exposure}

EDCs are exogenous substances that are able to mimic, block or modulate the action of natural hormones, jointly interact with the endocrine system, and subsequently caused adverse health effects in intact organisms. In the point of cellular mechanism, they may alter hormone synthesis in the endocrine gland, or through altering transport of the hormone to the target organ by interfering with the activity of conjugation enzymes as well as by competing for binding to carrier proteins. Alternatively, they may act by competing with the hormone for binding to a receptor in target cells. Questions dealing with the detailed mechanism of action is not a goal of this review but follow articles describe a detailed molecular mechanism (Diamanti-Kandarakis et al. 2009, Darbre et al. 2018, La Merrill et al. 2020). EDCs are an extremely heterogeneous group of ubiquitous substances, and common sources are environmental pollutants or daily used commercial products. More than 85,000 man-made chemicals worldwide may affect your life. Around 1-2\% of them are recognized as EDCs and the number increase continually. Many types of EDCs are used in industrial solvents or detergents, and high amounts of EDCs were found in pesticides, paints, toys, metal cans, textiles, building materials as well as in food and beverage storage containers. Glues, thermal receipt papers, and personal care products also form the current part of the EDCs sources list. Although daily exposure to EDCs takes place through skin contact or inhalation, the largest risk is associated with food products. Several studies confirmed that plastic food packaging is the major source of EDCs in the human diet (Almeida et al. 2018, Wu et al. 2019). While relatively low concentrations of EDCs result in harmful effects, some kinds of these chemicals must be consumed at higher doses to produce a corresponding effect on human health because their hormonal binding activities are usually five or six times lower than $17 \beta$-estradiol. Overleaf a combination of EDCs at lower concentrations may result in an unknown low-level cocktail effect, thus posing a greater risk to the consumer (Slama et al. 2017, Rashid et al. 2020, Yilmaz et al. 2020). During the last decades, the concentration of EDCs dramatically grown. Several scientific authorities identify EDCs as a major environmental and public health problem. Detection of these chemicals in human serum, seminal plasma, follicular fluid as well in other tissue raises concerns that current exposure definitely disrupts human physiological functions. Until now it has been identified carcinogenic, hepatotoxic, nephrotoxic, immunotoxic, and reprotoxic effects, which seriously reduces the quality parameters of an individual's life (Braun, 2017, Qiu et al. 2018, Jambor et al. 2019, Sabir et al. 2020). A few years ago, evidence of a significant growth began to emerge of reproductive dysfunctions in males with direct connection to EDCs' action. The possible adverse effects have been taken into focus both regarding the effects of EDCs on the male reproductive system and with respect to its differential susceptibility towards these compounds. Previous experimental studies found a high level of EDCs toxicity in rodents, but nowadays there exist some epidemiological studies which have been describing human reprotoxic impacts in detail (Paoli et al. 2020, Yilmaz et al. 2020). The results showed that the global average sperm count dropped by half and that the sperm motility, viability, and acrosomal integrity significantly decreased. In addition, many types of reproductive abnormalities have been linked with poor 
semen quality, reduced testes weight, and prostate cancer development. EDCs may also disrupt molecular processes such as spermatogenesis, by interfering with germ cells and sperm-supporting cells as well as could affect steroidogenesis occurring in Leydig cells. Therefore, there is a challenging task to evaluate and monitor the potential impact of EDCs on human health and precisely identified the molecular mechanism of action (Donato et al. 2017, Sharma et al. 2020, Park et al. 2021).

\section{The hazardous effects of bisphenols on the male reproductive system}

Due to the wide usage of bisphenols in many areas, a high concentration of them is widespread into the environment thereby demonstrably increasing the risk of various diseases such as obesity, diabetes, cardiovascular disorders, immunological deficits as well as previously discussed reproductive abnormalities. Bisphenol A (BPA) and its alternatives are manufactured in large quantities in the world because it has been frequently used in many commercial and industrial applications especially as a component of paint, pesticides, food packaging, cosmetics products, canned foods, or household detergents. Basically, bisphenols do not occur naturally in the environment but are formed and released during manufacturing and industrial activities. Bisphenols are prepared by the acetone process when the acid or cation exchanger-catalyzed condensation of acetone with phenol. After the recovery and purification procedures, such as still and centrifugation, the dried crystals will be a high-quality product with a purity of over $99 \%$ useful for next processes and products. Their molecular properties depend on their physicochemical parameters and thus determine distribution in the environment. The chemical structures of bisphenols consisting of two phenol nuclei linked by an alkyl bridge. Overleaf, specific parameters such as melting point, density, and others are mainly depending on the purity of the sample and its impurities, which reflect the manufacturing process and the manufacturer (Siracusa et al. 2018, vom Saal et al. 2020). Nowadays, BPA is considered one of the most well-studied EDCs with a clear effect on the child's development, nervous system, metabolic disorders, breast, or prostate cancer, and it is significantly implicated in causing many reproductive disruptions. The concern about the direct negative interaction of BPA with child development started a process for banning BPA-containing products for babies in the European
Union. Based on another negative effect on human health, the corporates have been started to quickly formulate new "BPA-free" plastics to be used as food packaging and food containers instead. These products are made using bisphenol analogues such as bisphenol $\mathrm{F}$, bisphenol AF, bisphenol Z, bisphenol B, or bisphenol S. Current information about the potential effect of these analogues is very limited and the mechanism of action is still not completely understood. Unfortunately, bisphenol still enters the human body where could initiate different changes on molecular, cellular, tissue, and organ levels (Vandenberg et al. 2013, Eladak et al. 2015). In view of all mentioned facts, we would like to summarize some relevant studies in relation to bisphenols and the men's reproductive system and reveal possible concerns about the direct interaction/exposure.

\section{Role of Bisphenol $A$ in men's reproductive health}

A survey of the PubMed database with the use of BPA as keywords provided more than 5,000 articles published during the last 5 years including clinical, experimental, and epidemiological studies. Many of them monitor the impact of BPA on the male reproductive system and examine their mutual interaction, the molecular mechanism of action, changes in signaling pathways, and cellular responses as well. Moreover, BPA played and still has a major role in the emergence of new concepts in the EDCs field. BPA (2,2-bis(4hydroxyphenol)propane) is considered one of the oldest synthetic compounds known for its endocrine activity. BPA could be polymerized to make polycarbonate plastic that is lightweight, transparent, colorable, and easy to mold and thermoform. The purity varies from $99 \%$ to $99.8 \%$ depending upon the manufacturer. Impurities typically include phenol $(<0.06 \%)$ ortho and para isomers of BPA $(<0.2 \%)$, water $(<0.2 \%)$, and others. A moderately high-water solubility and low vapor pressure indicate a significant bio-accumulative potential. Due to its chemical properties, BPA rapidly became one of the most produced/used chemicals worldwide. BPA is a stable component of variety common products such as paints, pesticides, construction materials, packaging, thermal cash register papers, and many others. However, using epoxy resins that are frequently used to coat the inner surface of food and beverage metallic cans has become a potential issue in the human diet. At the same time, biomonitoring and kinetic's studies have reached 
seemingly conflicting conclusions (Vandenberg et al. 2013, Wazir and Mokbel 2019). Ubiquitous distribution leads to contamination through the skin, or via inhalation of household dust. However, canned food, beverage containers, and plastic packaging are the main source of oral contaminations. The toxicokinetic of BPA exposure reveals that after oral contamination in humans, BPA is metabolized in the liver or intestine. BPA is not fully metabolized, but it is rapidly conjugated with glucuronic acid to produce non-active BPA-glucuronide. A little amount of BPA also reacts with sulfate to form a BPA-sulphate substance. These conjugates are subsequently excreted by the urine with terminal halflives of less than 6 hours (Volkel et al. 2002). Previous studies reported that the concentration of unconjugated BPA has an average concentration of 1 to $3 \mathrm{ng} / \mathrm{ml}$. However, some studies reported that unconjugated BPA represents no more than $2 \%$ of the total BPA in blood. This suggests that the total amount of BPA could be much higher than originally thought. Based on these facts, it is essential to monitor the content of BPA fractions as well as identify the possible cellular mechanism of action that could negatively affect reproductive health in males (Teeguarden et al. 2011).

\section{Human evidence of BPA risks}

Until today there have been reported plenty of male reproductive function abnormalities caused by BPA with an expected increase over the coming years. Many epidemiological studies examined the associations between BPA exposure and sperm production, sperm concentration, and sperm quality. Li et al. (2011) present evidence of an association between BPA exposure biomarker (urine BPA levels) and declining human semen quality. Specifically, an increasing urine BPA level was associated with lower semen concentrations $(\mathrm{P}<0.001)$, lower total sperm count, lower sperm vitality $(\mathrm{P}<0.001)$, and decreased sperm motility $(\mathrm{P}<0.001)$. However, the urine BPA level did not affect the semen volume or sperm morphology. The results also demonstrated a dose-response relationship between growing urine BPA levels and reduction in sperm motility, vitality, and concentrations among those with low environmental BPA exposure levels as well as those with high BPA exposure levels from the workplace. Similarly, to the previous study, Knez et al. (2014) investigated the relationship between environmental BPA exposure and reproductive parameters, including semen quality. BPA was detected in $98 \%(n=146)$ of men's urine samples with the average level at $1.55 \mathrm{ng} / \mathrm{ml}$. The results revealed an inverse association to total sperm count, sperm concentration, and sperm vitality $(\mathrm{P}<0.05)$. This means that with an increasing concentration of BPA in the samples, all of the sperm characteristics showed a significant decline value. Although human data is inconclusive in certain cases, the existing evidence suggests that serum or plasma BPA concentrations are not necessarily linked with sperm parameters, this dependency is seen in connection to BPA concentrations in seminal plasma (Tomza-Marciniak et al. 2018). A group of 308 healthy, young men from the general population have been chosen to examine the correlation between urinary BPA concentrations and semen quality or reproductive hormones. In this study, a higher BPA excretion was not associated with changes in semen volume, sperm concentrations, or percentage morphologically defect sperms. However, a significant inverse association was recorded at progressive motility of human spermatozoa (Lassen et al. 2014). Relationship between low/medium urinary bisphenol A concentrations and parameters indicating poor seminal quality, such as total sex chromosome disomy of sperm, increased percentage of immature sperm, and decreased motility was observed in two studies (Li et al. 2011, Radwan et al. 2018). Moreover, Krzastek et al. 2020 proposed the following impacts on male fertility: reduced sperm counts, motility, concentration, increased DNA damage and according to their study, hypothesized mechanisms of action are weak estrogen agonism and decreased androgen receptor expression. The objective of the next study was to investigate the alterations in men's reproductive functions due to evidence about higher BPA levels in urine samples. Semen quality was evaluated by measuring total sperm count, sperm concentrations, and sperm morphology or motility. Significant changes were recorded in both sperm concentration $(\mathrm{P}<0.01)$ and total sperm count, where increased BPA levels were associated with a decrease that was $19 \%$ of the median (Aboamnei et al. 2018). Increasing concentrations of BPA in men's urine samples was also confirmed by Goldstone et al. (2015). Linear and logistic regression models assessed the association between urinary BPA levels and individual semen quality endpoints. The average value of total urinary BPA concentrations was $0.55 \mathrm{ng} / \mathrm{ml}$ in this experimental study. Further, the total urinary BPA concentration among men's participants was lower than that observed in the previous study. Their analysis also suggests that lower urinary BPA level could be associated 
with less sperm DNA fragmentation, while significant abnormal sperm chromatin structure caused by BPA exposure has been reported previously (Meeker et al. 2010). The same study evaluated direct linking between urinary BPA concentrations and serum steroid hormone production in 167 men recruited through an infertility clinic. Increasing level of BPA was detected in $89 \%$ of urine samples with a maximum concentration of $36.4 \mathrm{ng} / \mathrm{ml}$. These findings also confirmed an inverse association between urinary BPA levels and the serum estradiol $\left(E_{2}\right)$ : testosterone $(T)$ ratio. Since estradiol is produced through the aromatization of testosterone, a reduction in the $E_{2}: T$ ratio is considered a marker for declined aromatase activity, which was confirmed by previous animal studies (Akingbemi et al. 2004). Child and adolescent male and female participants were selected in the next study carried out by Scinicariello and Buser (2016). They examined the association of BPA with serum testosterone levels. The average concentration of urinary BPA levels varied between 1.74 to $1.94 \mathrm{ng} / \mathrm{ml}$ and the results suggest an inverse association with serum testosterone levels. The concentration of testosterone was significantly reduced in men's adolescents while a higher amount of testosterone was observed in female adolescents. Liu et al. (2015) determined whether urinary BPA level could affect serum reproductive hormone levels among men adults. The urine and blood samples were collected from 592 recruited workers. More than $76 \%$ of samples had concentrations of BPA above $0.31 \mathrm{ng} / \mathrm{ml}$. An increased urine BPA level was associated with increased concentration of sex hormone-binding globulin (SHBG) and $\mathrm{E}_{2}$ level followed by a reduction in androstenedione level. The mutual interaction between the level of male reproductive hormones and BPA concentrations in men's urine samples was also investigated by Aboamnei et al. (2018). Serum samples were analyzed for follicle-stimulating hormone (FSH), luteinizing hormone ( $\mathrm{LH})$, testosterone, inhibin $\mathrm{B}$, and $\mathrm{E}_{2}$. A positive association was confirmed at $\mathrm{LH}$ levels, where urinary BPA concentrations were associated with an increase in LH that was almost $10 \%$. On the other hand, testosterone, $\mathrm{E}_{2}$, and inhibin $\mathrm{B}$ levels did not differ depending on BPA levels significantly. Galloway et al. (2010) monitored an association of urinary BPA levels and male reproductive hormones among 307 men randomly selected in Tuscany, Italy. The average level of urinary BPA was almost $3.6 \mathrm{ng} / \mathrm{ml}$. The results revealed no association between BPA excretion and 17 $\beta$-estradiol blood level. Overleaf, an association between BPA excretion and total testosterone concentrations has been found. The level of testosterone has been significantly increased in the majority of urine samples. Nevertheless, several other studies did not see significant associations between urinary BPA level and reproductive health in men (Chen et al. 2013, Den Hond et al. 2015). A growing body of evidence indicates that BPA action is initiated through binding to relatively specific hormone receptors, including sex hormone receptors (ERs and ARs), thereby directly regulating gene expression (Cimmino et al. 2020). Evidence regarding the BPA exposure and reproductive human health is not unambiguously conclusive due to a limited number of studies and a high variety in men's groups with emphasis on genetic predisposition and environmental conditions. Current ambiguous conclusions in men's reproductive alterations could be solved due to the exact determination of the molecular mechanism of BPA action using the animal in vitro and in vivo models.

\section{Role of Bisphenol $S$ in men's reproductive health}

Using the keywords bisphenol S (BPS) in the PubMed database, we found over 3,000 publications published in the last five years, demonstrating that BPS is substantially more researched than BPB. Bisphenol S (bis(4-hydroxyphenyl)sulphone) is a BPA analogue that is used in a variety of industrial applications, for example, as a constituent of cleaning products, an electroplating solvent as well as in the manufacture of polycarbonate plastic and paper products, especially thermal paper due to its higher thermal stability (Lotti et al. 2011, Pivnenko et al. 2015). Based on broad-spectrum usage the concerns about increased exposure to BPS have been resonating during the past years. In daily used products such as hair care products, lotions, toothpaste or makeups were detected undue concentrations of BPS. Especially, dairy products, meat products, vegetables, cereals, or a canned food have become the main source of BPS in humans (Liao and Kannan 2014b). Massive substitution of BPA by BPS and other substitutes evoked conviction, that these "safe alternatives" could be less toxic without significant harmful effects. Unfortunately, many chemical replacements are not sufficiently tested before being placed on the market, and in the case of bisphenols are significantly similar to original bisphenol A, what may initiate a serious concern. BPS is chemical and a structural analogue to BPA, thus its effect in the 
physiological system could be similar. In humans, BPS has been detected in urine samples at concentrations and frequencies comparable to BPA. According to Zhou et al. (2014), more than $78 \%$ of urine samples with a median concentration of $0.13 \mathrm{~g} / \mathrm{l}$ were found in adult volunteers in Atlanta. Liao et al. (2012) monitored 315 urine samples, collected from the general populations in the United States, China, India, Vietnam, Japan, and Korea for the presence of total BPS concentrations. BPS was detected in $81 \%$ of the urine samples with the highest mean concentration in Japan, followed by the United States and China. In addition, this study confirmed the daily intake of BPS at 0.02 to $1.7 \mu \mathrm{g}$ per person. These findings show that human susceptibility to BPS exists, and a significant increase is expected in the coming years.

\section{Human evidence of BPS risks}

BPS exposure has been attributed to a variety of negative health effects, including obesity, cardiovascular disorders, or reproductive toxicity (Héliès-Toussaint et al. 2014, Desdoits-Lethimonier et al. 2017, Zhang et al. 2020). The human reproductive system is especially vulnerable to BPA action and Ghayda et al. (2019) indicate similar negative consequences of BPS on semen quality. The present study determined whether urinary BPS concentrations could affect semen quality. This cross-sectional analysis included 158 men contributing 338 paired urine and semen samples (repeated measures), the semen samples were collected during the same day and at the same time as the urine sample for the analysis of bisphenol concentrations. They detected BPS in $76 \%$ of men and found associations of urinary BPS concentrations with lower ejaculate volume, sperm concentration, total count, and sperm motility, in adjusted models and models further adjusted for urinary BPS concentrations. Some of these associations were only observed among overweight and obese men, but not among leaner men. One possible hypothesis for this interesting finding is that overweight/obese men may be more sensitive to BPS exposure given that they are simultaneously exposed to a hyperestrogenic environment since obesity increases circulating estrogen levels in men together with antiandrogenic signal, since BPS has antiandrogenic activity (Usman and Ahmad 2016). However, Castellini et al. (2021) verified whether BPS could represent a safer compound for human sperm functions. The exposure of motile sperm suspensions to scalar concentrations of BPS for $4 \mathrm{~h}$ did not significantly reduce sperm motility (as assessed by computer-aided semen analysis) and viability. At flow cytometry, no changes in mitochondrial membrane potential, or mitochondrial generation of reactive oxygen species were detected by using the JC-1 and MitoSOX red probes, respectively. According to the results of their study, BPS seems to be safer alternatives to BPA for sperm biology, as it does not affect mitochondrial functions, sperm motility, and viability (Castellini et al. 2021). DesdoitsLethimonier et al. (2017) determined whether BPS ex vivo exposure affected adult human testes from prostate cancer patients. According to the results, applied doses of BPS $\left(10^{-9}\right.$ to $\left.10^{-5} \mathrm{M}\right)$ did not impair the histology of human testes. Overleaf, the production of testosterone was significantly $(\mathrm{P}<0.05)$ stimulated at $10^{-6} \mathrm{M}$ after 24 hours followed by a non-significant decline at the highest dose. The observing growth was set at $17.8 \%$. The rises in concentrations of $10^{-7} \mathrm{M}$ and $10^{-6} \mathrm{M}$ at 24 hours were attenuated at 48 hours $(12 \%$ and $16.6 \%$, respectively). However, a higher concentration of BPS $\left(10^{-8} \mathrm{M}\right)$ significantly $(\mathrm{P}<0.05)$ inhibited testosterone production after 48 hours. The observing decline was set at $18.9 \%$. Lower doses $\left(10^{-7}\right.$ to $\left.10^{-5} \mathrm{M}\right)$ initiate a moderate increase of insulin-like factor 3 (INSL3) production by Leydig cells after 24 hours. Overleaf, prolonged time of exposure to 48 hours caused significant $(\mathrm{P}<0.05)$ growth at $10^{-9}$ and $10^{-8} \mathrm{M}$. In the case of inhibin $\mathrm{B}$ production by Sertoli cells were not observed any significant changes comparing to the control group. We conclude, based on existing understanding and evidence, that assessing the effects of BPS on male reproductive systems is difficult and may be problematic. A continuous discussion over the effects of low BPS levels is ongoing, focusing on both the potential for hormetic effects as well as the indirect implications of a disturbance in hormonal balance.

\section{Role of Bisphenol $B$ and Bisphenol $F$ in men's reproductive health}

A survey of the PubMed database using the keywords bisphenol B (BPB) provided less than 350 publications published in the last five years, indicating that BPB is significantly less researched than BPA. Bisphenol B (2,2-bis(4-hydroxyphenyl)butane) is a bisphenol $\mathrm{A}$ analogue used to make epoxy resins, the central carbon atom has an ethyl group instead of the methyl group present in BPA (Cunha and Fernandes 2010). BPB was discovered to have a slow aerobic and anaerobic biodegradation in comparison with BPA, which 
makes it more prone to bio-accumulation in nature. Moreover, BPB has a higher acute toxicity than BPA and it is slightly more cytotoxic (Chen et al. 2016, Russo et al. 2018). The US Food and Drug Administration (FDA) has authorized BPB as an indirect food additive for use in food-contact resinous and polymeric coatings, but it is not authorized in the EU under the European Regulation on Chemical Registration, Evaluation, Authorization, and Restriction. As a result, no EU registrant is required by law to have toxicological or ecotoxicological evidence. Nonetheless, BPB has been found in a variety of European foods, including canned foods (Fattore et al. 2015), commercial milk samples (Grumetto et al. 2013), beverages, and baby formula powder (Cunha et al. 2011), seafood (Cunha et al. 2012), and bottled water (Wang et al. 2020), which indicates its dietary exposure in humans. In addition, urine samples of Portuguese volunteers (Cunha and Fernandes, 2010) or in the serum of endometriotic women in Italy (Cobellis et al. 2009). In comparison to BPA, data on human exposure levels to BPB are extremely limited and BPB is still one of the least studied and detected bisphenol in the environment (Noszczynska and Piotrowska-Seget, 2018). Therefore, further investigation should be dedicated to assessing the impact of BPB on human health and reproduction.

According to a search of the PubMed database using the keywords bisphenol F (BPF), there were over 600 publications published in the last five years, indicating that $\mathrm{BPF}$ is more investigated than $\mathrm{BPB}$, but less so than BPA and BPS. Bisphenol $F$ is a member of the bisphenol family with the chemical name bis(4-hydroxyphenyl) methane. It has two phenol rings that are connected by methylene in its structure. BPF epoxy resins are becoming more prevalent due to their low viscosity and improved solvent resistance than BPA epoxy resins ( $\mathrm{Lu}$ et al. 2018). With its use in the manufacture of epoxy resins and polycarbonates, BPF has found a wide variety of industrial uses and is gradually replacing BPA. Therefore, BPF is used to make epoxy resin coatings, especially for high-solid/high-build systems like tank and pipe linings, industrial floors, road and bridge deck toppings, structural adhesives, grouts, and electrical varnishes, which require increased thickness and durability. Lacquers, varnishes, liners, adhesives, plastics, water filters, dental sealants, and food packaging are another consumer goods made with BPF (Fiege et al. 2000, Liao and Kannan 2014a). Together with BPS, BPF has also been recorded as a predominant bisphenol contaminant in foodstuffs such as meat products, fish and seafood, or fruits and vegetables. BPF accounting for $17 \%$ of the total applied bisphenols (Liao and Kannan, 2013, Liao and Kannan 2014b). BPF is absorbed by the oral route and then dispersed across the body, including the reproductive tracts and fetuses, after passing the placental barrier. National Health and Nutrition Examination Survey investigated the urinary levels of bisphenols in adults and children. More than $66 \%$ of urine samples were positive for BPF presence (Lehmler et al. 2018). It was also detected in $42-88 \%$ of a total of 616 urine samples obtained in the United States between 2000 and 2014, with geometric mean concentrations ranging from $0.15 \mathrm{~g} / 1$ to $0.54 \mathrm{~g} / 1$ as well as the human plasma at concentrations three times higher than BPA which suggested a shift in its use during the past years (Ye et al. 2015). These data demonstrate that human susceptibility to BPB and BPS exists and that this susceptibility is expected to increase significantly in the future years, there are rising concerns regarding excessive bio-accumulation and the resulting detrimental effect on male reproductive health.

\section{Human evidence of $B P B$ and $B P F$ risks}

Desdoits-Lethimonier et al. (2017) evaluated the effect of BPA analogues on human testes. Human adult testes obtained from prostate cancer patients were exposed to BPB and BPF from $10^{-9}$ to $10^{-5} \mathrm{M}$ during 24 and 48 hours. The results revealed that BPB did not significantly affect Sertoli cell functions, inhibin B secretion, and germ cell viability. However, a significant $(\mathrm{P}<0.05)$ decrease in testosterone production was observed at $10^{-7} \mathrm{M}$ of BPB after 24 hours. This decline was set at around $17 \%$. Similarly, testosterone secretion was significantly $(\mathrm{P}<0.05)$ inhibited at the same dose of BPB after 48 hours. A significantly $(\mathrm{P}<0.05)$ higher production of insulin-like factor 3 (INSL3) by Leydig cells was observed at the lowest dose $\left(10^{-9} \mathrm{M}\right)$ of BPB after 24 hours. In the case of 48 hours exposition with $\mathrm{BPB}$ at $10^{-6}$ and $10^{-5} \mathrm{M}$, INSL3 levels continued to increase consistently. The results of BPF examinations indicate no significant impact in the histological evaluation of donor testes. A significant decrease in testosterone production was observed at $10^{-6} \mathrm{M}$ after 24 hours and at $10^{-6} \mathrm{M}$ and $10^{-5} \mathrm{M}$ after 48 hours of treatment, which could indicate that the response to BPF was more sensitive in comparison with BPA and BPB. However, the doses of BPF, which were found to significantly inhibit testosterone, were much higher than the concentrations recorded in the body fluids. On the 
other hand, INSL production ensured by Leydig cells was slightly increased at $10^{-8} \mathrm{M}$ and $10^{-7} \mathrm{M}$ without significant impact. Prolonged time of cultivation caused moderate and non-significant decreased from $10^{-9} \mathrm{M}$ to $10^{-6} \mathrm{M}$ compared to the control. The production of inhibin $\mathrm{B}$ by Sertoli cells was positively affected at $10^{-8} \mathrm{M}$ and $10^{-7} \mathrm{M}$ after 24 and 48 hours without significant effects. Castellini et al. (2021) verified whether BPF could represent a safer compound for human sperm functions. The exposure of motile sperm suspensions to scalar concentrations of BPF for $4 \mathrm{~h}$ did not significantly reduce sperm motility (as assessed by computer-aided semen analysis) and viability. At flow cytometry, no changes in mitochondrial membrane potential, or mitochondrial generation of reactive oxygen species were detected by using the JC-1 and MitoSOX red probes, respectively. Interestingly, it nor even the combination of both BPS and BPF at the highest concentrations impaired sperm mitochondrial functions. According to the results of their study, BPF seems to be safer alternatives to BPA for sperm biology, as it does not affect mitochondrial functions, sperm motility, and viability (Castellini et al. 2021). Limited evidence is available of the ability of BPB and BPS to impair human male reproductive system. In epidemiological and animal model research, no clear consistent results have been achieved. As a result, we must assume that evidence is still being sought in this area. A summary of documented effects of bisphenols on testicular parameters in humans is presented in Figure 1.
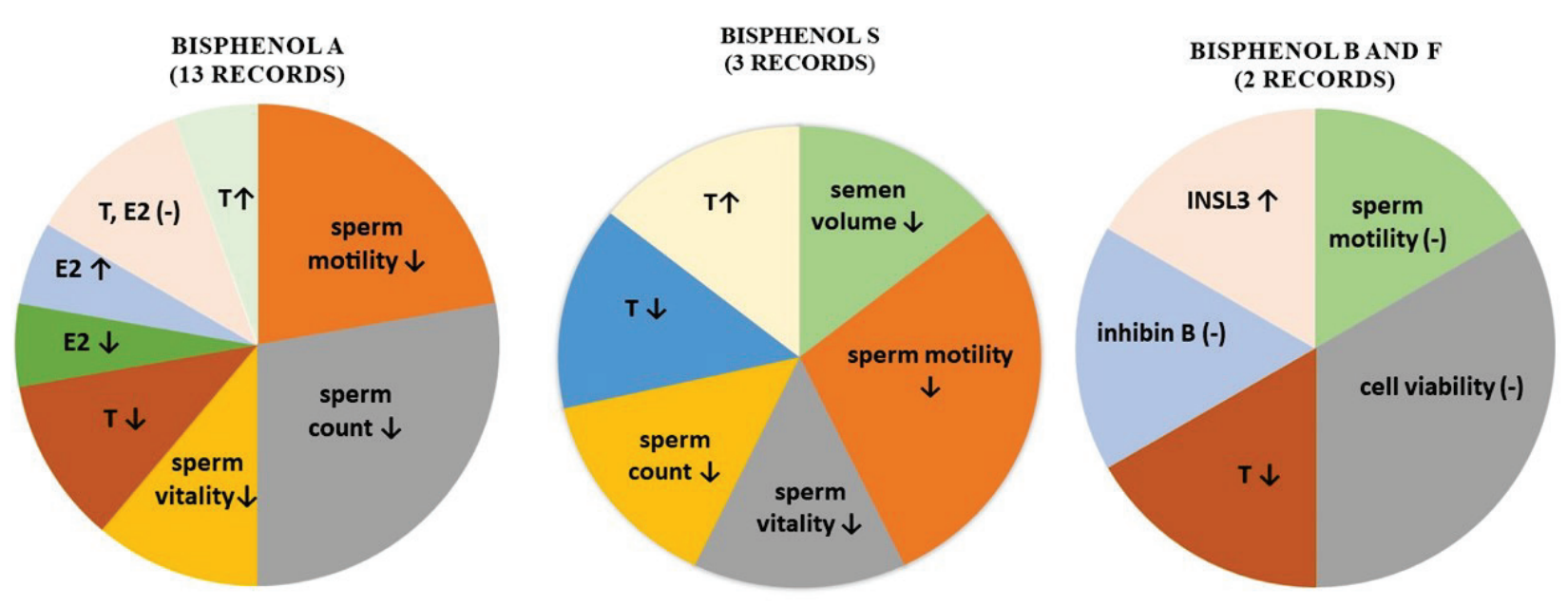

Fig. 1. The illustrative overview of the effects of bisphenols on testicular parameters in humans (- no change, $\downarrow$ decrease, $\uparrow$ increase). $\mathrm{T}$ - testosterone, E2 - estradiol, INSL3- insulin-like factor 3

\section{Conclusion and future perspectives}

Bisphenols are a challenging group of pollutants. They are highly dangerous and can exhibit a significant toxic effect due to the initiation of adverse health impacts at the lowest concentration in the environment. Although bisphenol A is gradually being replaced by other alternatives during the past years, their structural similarity appears to cause equally dangerous exposure, which could increase the risk of many reproductive alterations of the male reproductive system. Additional studies using more sensitive and reliable measurements of capture continuous bisphenols exposure and conduct semen and hormone analysis are required to determine if there is an association between bisphenols exposure and reproductive alterations in the general population. Overleaf, the cost per human sample processing is quite expensive. Based on these facts, the animals in vivo and in vitro models are a suitable alternative for identifying the mechanism of action as well as for monitoring changes in cellular, tissue, and organ. At the same time, it should be mentioned that different effects of bisphenols on reproduction have been observed depending on the using human or animal model. As a result, the use of nonoral routes of administration in many experimental conditions, different doses, the absence of dose-response relationships, or small numbers of test animals have complicated the interpretation of the results of toxicological and epidemiological studies about the effects of bisphenols. Therefore, to stop this vicious cycle it is crucial that humans develop environmental awareness to establish sustainability. As long as a change in attitude is not adopted by humanity, pollution by xenobiotics will continue to be a growing problem with 
huge potential to endanger the existence of life. Future generations' reproductive health will likely be determined by several factors, including governmental organizations to establish concentration limits, eliminate the use of some substances, and progressively control the use of agents with potential reproductive damage. This requires a preventive strategy rather than a reactionary one, which is the current regulatory paradigm. To summarize, additional research is needed to clarify the risk associated with BPA and its analogues exposure on male reproductive health. Based on available epidemiological evidence and experimental data, the effect of bisphenol analogues should be further investigated, particularly because, in comparison to extensive BPA research are those in alternatives are still limited.

\section{Conflict of Interest}

There is no conflict of interest.

\section{Acknowledgements}

This work was financially supported and by the Scientific Agency of the Slovak Republic VEGA No. 1/0083/21 and by the Slovak Research and Development Agency Grant no. APVV-16-0289, APVV- 20-0218.

\section{References}

ABOAMNEI E, MENDIOLA J, VELA-SORIA F, FERNÁNDEZ MF, OLEA N, JORGENSEN N, SWAN HS, TORRES-CANTERO AM: Urinary bisphenol A concentrations are associated with reproductive parameters in young men. Environ Res. 161: 122-128, 2018. https://doi.org/10.1016/j.envres.2017.11.002

AKINGBEMI BT, SOTTAS CHM, KOULOVA AI, KLINEFELTER GR, HARDY MP: Inhibition of testicular steroidogenesis by the xenoestrogen bisphenol A is associated with reduced pituitary luteinizing hormone secretion and decreased steroidogenic enzyme gene expression in rat Leydig cells. Endocrinology 145: 592-603, 2004. https://doi.org/10.1210/en.2003-1174

ALMEIDA S, RAPOSO A, GONZÁLES MA, CARRACOSSA C: Bisphenol A: food exposure and impact on human health. CRFSFS 17: 1503-1517, 2018. https://doi.org/10.1111/1541-4337.12388

ALWAAL A, BREYER BN, LUE TF: Normal male sexual function: emphasis on orgasm and ejaculation. Fertility and Sterility 104: 1051-1060, 2015. https://doi.org/10.1016/j.fertnstert.2015.08.033

BRAUN JM: Early-life exposure to EDCs: role in childhood obesity and neurodevelopment. Nat Rev Endocrinol 13: 161-173, 2017. https://doi.org/10.1038/nrendo.2016.186

BREMER AA, MILLER WL: Regulation of Steroidogenesis. In: Cellular Endocrinology in Health and Disease. Editor(s): Alfredo Ulloa-Aguirre, P. Michael Conn. Academic Press 2014, pp 207-227. https://doi.org/10.1016/B978-0-12-408134-5.00013-5

CASTELLINI C, TOTARO M, PARISI A, D'ANDREA S, LUCENTE L, CORDESCHI G, FRANCAVILLA S, FRANCAVILLA F, BARDONETTI A: Bisphenol A nad male fertility: Myths and realities. Front Endocrinol 11: 353-363, 2020. https://doi.org/10.3389/fendo.2020.00353.

CASTELLINI C, DI GIAMMARCO N, D'ANDREA S, PARISI A, TOTARO M, FRANCAVILLA S, FRANCAVILLA F, BARBONETTI A: Effects of bisphenol S and bisphenol F on human spermatozoa: An in vitro study. Reproductive Toxicology 103: 58-63, 2021. https://doi.org/10.1016/j.reprotox.2021.05.011

CHEN D, KANNAN K, TAN H, ZHENG Z, FENG YL, WU Y, WIDELKA M: Bisphenol Analogues Other Than BPA: Environmental Occurrence, Human Exposure, and Toxicity-A Review. Environ Sci Technol 50: 5438-53, 2016. https://doi.org/10.1021/acs.est.5b05387

CHEN M, TANG R, FU G, ZHU P, QIAO S, CHEN X, XU B, QIN Y, LU C, HANG B, XIA Y, WANG X: Association of exposure to phenols and idiopathic male infertility. J Hazard Mat 250-251: 115-121, 2013. https://doi.org/0.1016/i.jhazmat.2013.01.061

CIMMINO I, FIORY F, PERRUOLO G, MIELE C, BEGUINOT F, FORMISANO P, ORIENTE F: Potential mechanisms of Bisphenol A (BPA) contributing to human disease. Int J Molecular Sci 21: 5761, 2020. https://doi.org/10.3390/ijms21165761

CLAVIJO RI, HSIAO W: Update on male reproductive endocrinology. Translational Andrology and Urology 7: 367-372, 2018. https://doi.org/10.21037/tau.2018.03.25 
CLEMENT P, GIULIANO F: Anatomy and physiology of genital organs - men. Handb Clin Neurol 130: 19-37, 2015. https://doi.org/10.1016/B978-0-444-63247-0.00003-1

COBELLIS L, COLACURCI N, TRABUCCO E, CARPENTIERO C, GRUMETTO L: Measurement of bisphenol A and bisphenol B levels in human blood sera from healthy and endometriotic women. Biomed Chromatogr 23: 1186-90, 2009. https://doi.org/10.1002/bmc.1241

CUNHA SC, ALMEIDA C, MENDES E, FERNANDES JO: Simultaneous determination of bisphenol A and bisphenol $\mathrm{B}$ in beverages and powdered infant formula by dispersive liquid-liquid micro-extraction and heart-cutting multidimensional gas chromatography-mass spectrometry. Food Addit Contam Part A Chem Anal Control Expo Risk Assess 28: 513-26, 2011. https://doi.org/10.1080/19440049.2010.542551

CUNHA SC, CUNHA C, FERREIRA AR, FERNANDES JO: Determination of bisphenol A and bisphenol B in canned seafood combining QuEChERS extraction with dispersive liquid-liquid microextraction followed by gas chromatography-mass spectrometry. Anal Bioanal Chem 404: 2453-63, 2012. https://doi.org/10.1007/s00216$\underline{012-6389-5}$

CUNHA SC, FERNANDES JO: Quantification of free and total bisphenol A and bisphenol B in human urine by dispersive liquid-liquid microextraction (DLLME) and heart-cutting multidimensional gas chromatographymass spectrometry (MD-GC/MS). Talanta 83: 117-1250, 2010. https://doi.org 10.1016/j.talanta.2010.08.048

DARBRE PD: Overview of air pollution and endocrine disorders. Int J Gen Med 11: 191-207, 2018. https://doi.org/10.2147/IJGM.S102230

DEN HOND E, TOURNAYE H, DE SUTTER P, OMBELET Q, BAEYENS W, COVACI A, COX B, NAWROT TS, LAREBEKE NV, D'HOOGHE T: Human exposure to endocrine disrupting chmicals and fertility: a casecontrol study in male subfertility patients. Environ Inter 84: 154-160, 2015. https://doi.org/10.1016/j.envint.2015.07.017

DESDOITS-LETHIMONIER C, LESNÉ L, GAUDRIAULT P, ZALKO D, ANTIGNAC JP, DECEUNINCK Y, PLATEL C, DEJUCQ-RAINSFORD N, MAZAUD-GUITTOT S, JÉGOU B: Parallel assessment of the effects of bisphenol A and several of its analogs on the adult human testis. Hum Reprod 32: 1465-1473, 2017. https://doi.org/10.1093/humrep/dex093

DIAMANTI-KANDARAKIS E, BOURGUIGNON JP, GIUDICE LC, HAUSE R, PRINS GS, SOTO AM, ZOELLER T, GORE AC: Endocrine-disrupting chemicals: an endocrine society scientific statement. Endocr Rev 30: 293-342, 2009. https://doi.org/10.1210/er.2009-0002

DONATO DM, CERNERA G, GIOVANNELI P, GALASSO G, BILANCIO A, MIGLIACCIO A, CASTORIA G: Recent advances on bisphenol-A and endocrine disruptor effects on human prostate cancer. Mol Cell Endoc 457: 35-42, 2017. https://doi.org/10.1016/j.mce.2017.02.045

ELADAK S, TIPHANY G, DLPHINE M, GUERQUIN MJ, N'THUMBA-BYN T, POZZI-GAUDIN S, BENACHI A, LIVERA G, ROUILLER-FABRE V, HABER R: A new chapter in the bisphenol A story: bisphenol S and bisphenol $F$ are not safe alternatives to this compound. Fertil Steril 103: 11-21, 2015. https://doi.org/1010.1016/j.fertnstert.2014.11.005

FATTORE M, RUSSO G, BARBATO F, GRUMETTO L, ALBRIZIO S: Monitoring of bisphenols in canned tuna from Italian markets. Food Chem Toxicol 83: 68-75, 2015. https://doi.org/10.1016/j.fct.2015.05.010

FIEGE H, VOGES HW, HAMAMOTO T, UMEMURA S, IWATA T, MIKI H, FUJITA Y, BUYSCH HJ, GARBE D, PAULUS W: Phenol derivatives. Ullmann's Encyclopedia of Industrial Chemistry 643-647, 2000. https://doi.org/10.1002/14356007.a19 313

GALLOWAY T, CIPELLI R, GURALNIK J, FERRUCCI L, BANDINELLI S, CORSI MA, MONEY C, MCCORMACK P, MELZER D: Daily bisphenol A excretion and associations with sex hormone concentrations: results form the InCHIANTI adult population study. Environ Health Perspect 118: 1603-1608, 2010. https://doi.org/10.1289/ehp.1002367

GHAYDA RA, WILLIAMS PL, CHAVARRO JE, FORD JB, SOUTER I, CALAFAT AM, HAUSER R, MÍNGUEZALARCÓN L: Urinary bisphenol S concentrations: Potential predictors of and associations with semen quality parameters among men attending a fertility center. Environ Int 131: 105050, 2019. https://doi.org/10.1016/j.envint.2019.105050

HEALTHDIRECT: Male reproductive system 2021. https://www.healthdirect.gov.au/male-reproductive-system 
GOLDSTONE AE, CHEN Z, PERRY MJ, KANNAN K, LOUIS BMG: Urinary bisphenol A and semen quality, the LIFE study. Reprod Toxicol 51: 7-13, 2015. https://doi.org/10.1016/j.reprotox.2014.11.003

GRUMETTO L, GENNARI O, MONTESANO D, FERRACANE R, RITIENI A, ALBRIZIO S, BARBATO F: Determination of five bisphenols in commercial milk samples by liquid chromatography coupled to fluorescence detection. J Food Prot 76: 1590-1596, 2013. https://doi.org/10.4315/0362-028X.JFP-13-054

HÉLIÈS-TOUSSAINT C, PEYRE L, COSTANZO C, CHAGNON MC, RAHMANI R: Is bisphenol S a safe substitute for bisphenol A in terms of metabolic function? An in vitro study. Toxicol Appl Pharmacol 280: 224-235, 2014. https://doi.org/10.1016/j.taap.2014.07.025

IBOR OR, ADEOGUN AO, REGOLI F, ARUKWE A: Xenobiotic biotransformation, oxidative stress and obesogenic molecular biomarker responses in Tilapia guineensis from Eleyele Lake, Nigeria. Ecotoxicol Environ Saf 169: 255-265, 2019. https://doi.org/10.1016/j.ecoenv.2018.11.021

ITTMANN M: Anatomy and Histology of the Human and Murine Prostate. Cold Spring Harbor Perspectives in Medicine 8: a030346, 2018. https://doi.org/10.1101/cshperspect.a030346

JAMBOR T, KOVACIKOVA E, GREIFOVA H, KOVACIK A, LIBOVA L, LUKAC N: Assessment of the effective impact of bisphenols on mitochondrial activity and steroidogenesis a dose-dependency in mice TM3 Leydig cells. Physiol Res 4: 689-693, 2019. https://doi.org/10.33549/physiolres.934200

KNEZ J, KRANVOGL R, BREZNIK BP, VONČINA E, VLAISAVLJEVIC V: Are urinary bisphenol A levels in men related to semen quality and embryo development after medically assisted reproduction? Fertil Steril 101: 215-221, 2014. https://doi.org/10.1016/j.fertnstert.2013.09.030

KRZASTEK SC, FARHI J, GRAY M, SMITH RP: Impact of environmental toxin exposure on male fertility potential. Translational Androl Urol 9: 2797-2813, 2020. https://doi.org/10.21037/tau-20-685

LA MERRILL MA, VANDENBERG LN, SMITH MT, GOODSON W, BROWNE P, PATISAUL HB, GUYTON KZ, KORTENKAMP A, COGLIANO VJ, WOODRUFF, TJ, RIESWIJK L, SONE H, KORACH KS, GORE AC, ZEIS L, ZOELLER RT: Consensus on the key characteristic of endocrine-disrupting chemicals as a basis for hazard identification. Nat Rev, Endocrinol 16: 45-57, 2020. https://doi.org/10.1038/s41574-019-0273-8

LASSEN TH, FREDERIKSEN H, JENSEN TK, PETERSEN JH, JOENSEN UN, MAIN KM, SKAKKEBAEK NE, JUUL A, JORGENSEN N, ANDERSSON AM: Urinary bisphenol A levels in young men: association with reproductive hormones and semen quality. Environ Health Persp 122: 478-484, 2014. https://doi.org/10.1289/ehp.1307309

LEHMLER HJ, LIU B, GADOGBE M, BAO W: Exposure to Bisphenol A, Bisphenol F, and Bisphenol S in U.S. Adults and children: the national health and nutrition examination survey 2013-2014. ACS Omega 3: 6523-6532, 2018. https://doi.org/10.1021/acsomega.8b00824

LI DK, ZHOU Z, MIAO M, HE Y, WANG JT, FERBER J, HERRINTON LJ, GAO E, YUAN W: Urine bisphenol-A (BPA) level in relation to semen quality. Fertil Steril 95: 625-630, 2011. https://doi.org/10.1016/j.fertnstert.2010.09.026

LIAO C, KANNAN K: A survey of alkylphenols, bisphenols, and triclosan in personal care products from China and the United States. Arch Environ Contam Toxicol 67: 50-9, 2014a. https://doi.org/10.1007/s00244-014-0016-8

LIAO C, KANNAN K: A survey of bisphenol A and other bisphenol analogues in foodstuffs from nine cities in China. Food Addit Contam Part A Chem Anal Control Expo Risk Assess 31: 319-329, 2014b. https://doi.org/10.1080/19440049.2013.868611

LIAO C, KANNAN K: Concentrations and profiles of bisphenol A and other bisphenol analogues in foodstuffs from the United States and their implications for human exposure. J Agric Food Chem 61: 4655-4662, 2013. https://doi.org/10.1021/jf400445n

LIAO C, LIU F, GUO Y, MOON HB, NAKATA H, WU Q, KANNAN K: Occurrence of eight bisphenol analogues in indoor dust from the United States and several Asian countries: implications for human exposure. Environ Sci Technol 46: 9138-9145, 2012. https://doi.org/10.1021/es302004w

LIU X, MIAO M, ZHOU Z, GAO E, CHEN J, WANG J, SUN F, YUAN W, LI DE: Exposure to bisphenol-A and reproductive hormones among male adults. Environ Toxicol Pharmacol 39: 934-941, 2015. https://doi.org/10.1016/j.etap.2015.03.007 
LOTTI N, COLONNA M, FIORINI M, FINELLI L, BERTI C: Poly(butylene terephthalate) modified with ethoxylated bisphenol S with increased glass transition temperature and improved thermal stability. Polymer 52: 904-911, 2011. https://doi.org/10.1016/j.polymer.2011.01.018

LU S, YU Y, REN L, ZHANG X, LIU G, YU Y: Estimation of intake and uptake of bisphenols and triclosan from personal care products by dermal contact. Sci Total Environ 621: 1389-1396, 2018. https://doi.org/10.1016/j.scitotenv.2017.10.088

MEEKER JD, EHRLICH S, TOTH TL, WRIGHT DL, CALAFAT AM, TRISINI AT, YE X, HAUSER R: Semen quality and sperm DNA damage in relation to urinary bisphenol A among men form an infertility clinic. Repro Toxi 30: 532-539, 2010. https://doi.org/10.1016/j.reprotox.2010.07.005

MEZZELANI M, GORBI S, REGOLI F: Pharmaceuticals in the aquatic environments: evidence of emerged threat and future challenges for marine organisms. Marine Environ Res 140: 41-60, 2018. https://doi.org/10.1016/j.marenvres.2018.05.001

NOSZCZYNSKA M, PIOTROWSKA-SEGET Z: Bisphenols: Application, occurrence, safety, and biodegradation mediated by bacterial communities in wastewater treatment plants and rivers. Chemosphere 201: 214-223, 2018. https://doi.org/10.1016/j.chemosphere.2018.02.179

PAOLI D, PALlOTTI F, DIMA AP, ALBANI E, ALVIGGI C, CAUSIO F, DIOGUARDI CC, CONFORTI A, CIRIMINNA, R, FABOZZI G: Phthalates and bisphenol A: presence in blood serum and follicular fluid of Italian women undergoing assisted reproduction techniques. Toxics 8: 1-15, 2020. https://doi.org/10.3390/toxics8040091

PARK HJ, LEE R, YOO H, HONG K, SONG H: Nonylphenol induces apoptosis through ROS/JNK signaling in a spermatogonia cell line. Int J Mol Sci 22: 307-321, 2021. https://doi.org/10.3390/ijms22010307

PIVNENKO K, PEDERSEN GA, ERIKSSON E, ASTRUP TF: Bisphenol A and its structural analogues in household waste paper. Waste Manag 44: 39-47, 2015. https://doi.org/10.1016/j.wasman.2015.07.017

QIU W, SHAO H, LEI P, ZHEN CH, QIU C, YANG M, ZHENG Y: Immunotoxicity of bisphenol S and F are similar to that of bisphenol A during zebrafish early development. Chemosphere 194: 1-8, 2018. https://doi.org/10.1016/j.chemosphere.2017.11.125

RASHID H, ALQAHTANI SS, ALSHAHRANI S: Diet: a source of endocrine disruptors. Endoc Met Immu Dis 20: 633-645, 2020. https://doi.org/10.2174/1871530319666191022100141

RADWAN M, WIELGOMAS B, DZIEWIRSKA E, RADWAN P, KAŁUŻNY P, KLIMOWSKA A, HANKE W, JUREWICZ J: Urinary Bisphenol A Levels and Male Fertility. American Journal of Men's Health 12: 2144-2151, 2018. https://doi.org/10.1177/1557988318799163

RUSSO G, CAPUOZZO A, BARBATO F, IRACE C, SANTAMARIA R, GRUMETTO L: Cytotoxicity of seven bisphenol analogues compared to bisphenol A and relationships with membrane affinity data. Chemosphere 201: 432-440, 2018. https://doi.org/10.1016/j.chemosphere.2018.03.014

SABIR S, REHMAN K, FIAYYAZ F, KAMAL S, AKASH MSH: Role of aflatoxins as EDCs in metabolic disorders. In: Endocrine Disrupting Chemicals - induced Metabolic Disorders and Treatment. AKASH MSH, REHMAN K, HASHMI MZ (eds), Springer International Publishing, 2020, pp 381-389. https://doi.org/10.1007/978-3030-45923-9 23

SAGHIR SA, ANSARI RA: Metabolism (Biotransfomation). Reference Module in Biomedical Sciences, 2019 - in press. https://doi.org/10.1016/B978-0-12-801238-3.07825-9

SALEM HM, Salam AA, SALAM AM, SELEIMAN MF: Soil xenobiotics and their phyto-chemical remediation. In: Xenobiotics in the Soil Environment. HASHIM M, KUMA V, VARMA A (eds), Springer International Publishing, 2017, pp 267-280. https://doi.org/10.1007/978-3-319-47744-2_18

SENGER P: Pathways to Pregnancy and Parturition. 1997. ISBN: 978-0965764803.

SCINICARIELLO F, BUSER MC: Serum testosterone concentrations and urinary bisphenol A, benzophenone-3, triclosan and paraben levels in male and female children and adolescent: NHANES 2011-2012. Environ Health Perspect 124: 1898-1904, 2016. https://doi.org/10.1289/EHP150

SHARMA A, MOLLIE J, BROCKLESBY RWK, CAVES CH, JAYASENA CHN, MINHAS S: Endocrine-disrupting chemicals and male reproductive health. Rep Med Biol 19: 243-253, 2020. https://doi.org/10.1002/rmb2.12326 
SIRACUSA JS, YIN L, MEASEL E, LINAG S, YU X: Effect of bisphenol A and its analogs on reproductive health: a mini review. Rep Toxi 79: 96-123, 2018. https://doi.org/10.1016/j.reprotox.2018.06.005

SLAMA R, VERNET C, NASSAN FL, HAUSE R, PHILIPPAT C: Characterizing effect of endocrine disruptors on human health: the role of epidemiological cohorts. Comp Rend Biol 340: 421-431, 2017. https://doi.org/10.1016/j.crvi.2017.07.008

SUSSMAN EM, CHUDNOVSKY A, NIEDERBERGER CS: Hormonal Evaluation of the Infertile Male: Has It Evolved? Urologic Clinics of North America 35: 147-155, 2008. https://doi.org/10.1016/j.ucl.2008.01.010

TEEGUARDEN JG, CALAFAT AM, YE X, DOERGE DR, CHURCHWELL MI, GUNAWAN R, GRAHM MK: Twenty-four hour human urine and serum profiles of bisphenol A during high-dietary exposure. Toxicol Sci 123: 48-57, 2011. https://doi.org/10.1093/toxsci/kfr160

TOMZA-MARCINIAK A, STĘPKOWSKA P, KUBA J, PILARCZYK B: Effect of bisphenol A on reproductive processes: A review of in vitro, in vivo and epidemiological studies. J Applied Toxicol 38: 51-80, 2018. https://doi.org/10.1002/jat.3480

USMAN A, AHMAD M: From BPA to its analogues: Is it a safe journey? Chemosphere 158: 131-42, 2016. https://doi.org/10.1016/j.chemosphere.2016.05.070

VANDENBERG LN, HUNT PA, MYERS JP, VOM SAAL FS: Human exposures to bisphenol A: mismatches between data and assumptions. Rev Environ Health 28: 37-58, 2013. https://doi.org/10.1515/reveh-2012-0034

VOLKEL W, COLNOT T, CSANÁDY GA, FILSER JG, DEKANT W: metabolism and kinetics of bisphenol A in humans at low doses following oral administration. Chem Res Toxicol 15: 1281-1287, 2002. https://doi.org/10.1021/tx025548t

VOM SAAL SF, VANDENBERG LN: Update on the health effects of bisphenol A: overwhelming evidence of harm. Endocrinology 162: 171, 2020. https://doi.org/10.1210/endocr/bqaa171

WANG H, LIU ZH, TANG Z, ZHANG J, YIN H, DANG Z, WU PX, LIU Y: Bisphenol analogues in Chinese bottled water: Quantification and potential risk analysis. Sci Total Environ 713: 136583, 2020. https://doi.org/10.1016/j.scitotenv.2020.136583

WAZIR U, MOKBEL K: Bisphenol A: a concise review of literature and discussion of health and regulatory implications. In vivo 33: 1421-1423, 2019. https://doi.org/10.21873/invivo.11619

WU H, WU LH, WANG F, GAO CHJ, CHEN D, GUO Y: Several environmental endocrine disruptors in beverages from south China: occurrence and human exposure. Environ Sci Poll Res 26: 5873-5884, 2019. https://doi.org/10.1007/s11356-018-3933-7

YE X, WONG LY, KRAMER J, ZHOU X, JIA T, CALAFAT AM: Urinary Concentrations of Bisphenol A and Three Other Bisphenols in Convenience Samples of U.S. Adults during 2000-2014. Environ Sci Technol 49: 11834-9, 2015. https://doi.org/10.1021/acs.est.5b02135

YILMAZ B, TEREKECI H, SANDAL S, KELESTIMUR F: Endocrine disrupting chemicals: exposure, effects on human health, mechanism of action, models for testing and strategies for prevention. Rev Endocr Metab Disord 21: 127-147, 2020. https://doi.org/10.1007/s11154-019-09521-z

ZHANG YF, SHAN CH, WANG Y, QIAN LL, JIA DD, ZHANG YF, HAO XD, XU HM: Cardiovascular toxixity and mechanism of bisphenol A and emerging risk of bisphenol S. Sci Tot Environ 723: 137952, 2020. https://doi.org/10.1016/j.scitotenv.2020.137952

ZHOU X, KRAMER JP, CALAFAT AM, YE X: Automated on-line column-switching high performance liquid chromatography isotope dilution tandem mass spectrometry method for the quantification of bisphenol A, bisphenol F, bisphenol S, and 11 other phenols in urine. J Chromatogr B Analyt Technol Biomed Life Sci 944: 152-156, 2014. https://doi.org/10.1016/j.jchromb.2013.11.009 